\title{
Breast Cancer Screening in Older Women: The Importance of Shared Decision Making
}

\author{
Sarina Schrager, MD, MS, Viktoriya Ovsepyan, BA, and \\ Elizabeth Burnside, MD, MS, MPH
}

Incidence of breast cancer increases with age up until age 80. Screening mammography has demonstrated efficacy in decreasing mortality from breast cancer among women between 50 and 74 years of age. However, most major organizations do not include women over 74 in their recommendations due to the lack of evidence in this age-group. This article will review current recommendations for breast cancer screening in women over the age of 74 . It will also present clear guidelines for primary care clinicians to follow that incorporate shared decision-making techniques, tools for estimating the risks and benefits of screening mammography, and strategies for integrating a patient's life expectancy and comorbidities into the decision-making process. We also emphasize the importance of using thoughtful communication strategies to fully engage older women in the breast cancer screening discussion. ( $\mathrm{J}$ Am Board Fam Med 2020;33:473-480.)

Keywords: Breast Cancer, Communication, Early Detection of Cancer, Incidence, Mammography, Primary Health Care, Risk Assessment, Shared Decision Making

\section{Case}

Ms. Brown is a 76-year-old woman with well-controlled hypertension but no other medical problems. She comes in for a physical. You bring up breast cancer screening and discuss the mixed recommendations for continuing screening mammography in women over 74 . What should you tell her?

\section{Background}

Age is the major risk factor for breast cancer. Breast cancer accounts for $30 \%$ of all new cancer diagnoses in women. ${ }^{1}$ Breast cancer deaths have declined significantly in the United States due to improvements

\footnotetext{
This article was externally peer reviewed.

Submitted 16 October 2019; revised 17 December 2019; accepted 18 December 2019.

From the University of Wisconsin Department of Family Medicine and Community Health, Madison (SS); the University of Wisconsin School of Medicine and Public Health, Madison (VO); and the University of Wisconsin Department of Radiology, Madison (EB).

Funding: There has been no extramural funding to support this work.

Prior presentation: This work has not been presented or submitted to another journal for publication.

Conflict of interest: None.

Corresponding author: Sarina Schrager, MD, MS, University of Wisconsin Department of Family Medicine and Community Health, 1100 Delaplaine Ct, Madison, WI 53715 (E-mail: sbschrag@wisc.edu).
}

in early detection and treatment efficacy, but breast cancer still accounts for $30 \%$ of all new cancer diagnoses in women. ${ }^{1}$ Approximately $41 \%$ of all incident breast cancers and $57 \%$ of all breast cancer deaths occur among women aged 65 years and older. ${ }^{2}$ Furthermore, women $\geq 65$ who develop breast cancers have higher death rates and poorer outcomes. ${ }^{3-5}$ The incidence of breast cancer continues to increase until age $80 .^{6}$

Screening mammography has been shown to be effective in reducing breast cancer mortality in women aged 50 to 74 years. ${ }^{3}$ However, because none of the randomized trials of screening mammography included women over the age of 74 , and very few trials included women over the age of 70 , screening recommendations for older women are lacking and remain controversial. The decision to continue screening in women over the age of 74 should be individualized, taking into account potential benefits and harms of screening in the context of a woman's overall health, life expectancy, and values. This article aims to provide a guide for primary care clinicians who take care of women over the age of 74 .

\section{Screening Guidelines for Women over 74}

Most guidelines suggest that breast cancer screening should continue until the age of 74 , but beyond 


\begin{tabular}{|c|c|c|}
\hline Source (Year Issued) & Should Women in Their 70s Get Mammograms? & $\begin{array}{l}\text { If Yes, How } \\
\text { Frequently? }\end{array}$ \\
\hline $\begin{array}{l}\text { Siu and US Preventive Services Task } \\
\text { Force }(2016)^{9}\end{array}$ & $\begin{array}{l}\text { Yes, until age } 74 \text {. } \\
\text { Beyond age } 74: \text { no recommendation due to insufficient evidence. If } \\
\text { offered, patients should understand the uncertainty about the } \\
\text { balance of benefits and harms. }\end{array}$ & Every 2 years \\
\hline $\begin{array}{l}\text { Oeffinger et al/American Cancer } \\
\text { Society }(2015)^{7}\end{array}$ & $\begin{array}{l}\text { Yes. } \\
\text { Continue screening as long as a patient has good overall health and } \\
\text { a life expectancy of } 10 \text { years or longer. }\end{array}$ & 1 to 2 years \\
\hline $\begin{array}{l}\text { Qaseem et al/American College of } \\
\text { Physicians }(2019)^{8}\end{array}$ & $\begin{array}{l}\text { Yes, until age } 74 \text {. } \\
\text { Beyond age } 74 \text { : screening not recommended. Patients aged } 75 \\
\text { years or older, or of any age if they have serious health } \\
\text { conditions, are unlikely to benefit yet still experience harms } \\
\text { from screening and treatment. }\end{array}$ & Every 2 years \\
\hline $\begin{array}{l}\text { American Academy of Family } \\
\text { Physicians (2016) }\end{array}$ & $\begin{array}{l}\text { Yes, until age } 74 \text {. } \\
\text { Beyond age } 74 \text { : no recommendation due to insufficient evidence. If } \\
\text { offered, patients should understand the uncertainty about the } \\
\text { balance of benefits and harms. }\end{array}$ & Every 2 years \\
\hline $\begin{array}{l}\text { American College of Obstetricians } \\
\quad \& \text { Gynecologists }(2017)^{48}\end{array}$ & $\begin{array}{l}\text { Yes, until age } 75 \text {. } \\
\text { Beyond age } 75 \text { : decision to stop screening should be based on a } \\
\text { shared decision-making process that includes a discussion of the } \\
\text { patient's health status and longevity. }\end{array}$ & 1 to 2 years \\
\hline $\begin{array}{l}\text { Moticciolo et al/American College } \\
\text { of Radiology }(2017)^{49}\end{array}$ & $\begin{array}{l}\text { Yes } \\
\text { The age to stop screening should be based on each patient's health } \\
\text { status rather than an age-based determination. Screening } \\
\text { recommendations should be tailored to individual circumstances } \\
\text { such as life expectancy, comorbidities, and the intention to seek } \\
\text { (and ability to tolerate) treatment if a cancer is detected. }\end{array}$ & Every year \\
\hline $\begin{array}{l}\text { Canadian Task Force on Preventive } \\
\text { Health Care }(2018)^{50}\end{array}$ & $\begin{array}{l}\text { Yes, until age } 74 \text {. } \\
\text { Beyond age } 74 \text { : no recommendation due to insufficient evidence. }\end{array}$ & 2 to 3 years \\
\hline $\begin{array}{l}\text { National Health Service, United } \\
\text { Kingdom }(2015)^{51}\end{array}$ & $\begin{array}{l}\text { Yes, until age } 73 \text {. } \\
\text { Beyond age } 73 \text { : no recommendation, but patients remain eligible } \\
\text { for screening. }\end{array}$ & Every 3 years \\
\hline $\begin{array}{l}\text { Royal Australian College of General } \\
\text { Practitioners }(2018)^{52}\end{array}$ & $\begin{array}{l}\text { Yes, until age } 74 \text {. } \\
\text { Beyond age } 74 \text { : no recommendation due to insufficient evidence } \\
\text { from randomized trials. However, observational studies favor } \\
\text { extending screening to patients with a life expectancy of at least } \\
10 \text { years. }\end{array}$ & Every 2 years \\
\hline
\end{tabular}

that age, professional organizations differ in their recommendations (Table 1). The American Cancer Society advises physicians to continue screening patients as long as they are in "good overall health" and have a life expectancy of 10 year or longer, ${ }^{7}$ whereas the American College of Physicians recommends screening stop at age $74 .{ }^{8}$ The United States Preventive Services Task Force offers no recommendation, due to insufficient evidence. ${ }^{?}$

\section{Benefits and Harms}

Although randomized trials did not include women over the age of 74 , observational studies have shown a reduction in breast cancer mortality associated with mammographic detection of breast cancer in women 75 years and older. ${ }^{10}$ Modeling studies have also shown that continuing biennial screening to age 79 years (vs 69 years) reduces breast cancer mortality by $6 \%$ to $10 \% .{ }^{11}$ When biennial screening mammography is continued into a woman's 70s (rather than until age 69), 2 fewer women per 1000 die from breast cancer after 10 years. ${ }^{12}$ The specificity and sensitivity of mammography improves with older age. Mammography in women older than 80 years has a sensitivity of $86 \%$ and specificity of $94 \%$ (vs sensitivity $=73 \%$ and specificity $=92 \%$ in 50 -yearold women). ${ }^{13}$ As women age, the proportion of invasive ductal cancer versus ductal carcinoma in situ cases rises, while the proportion of cases with positive nodes decreases. ${ }^{14}$ Elderly women who forgo screening are more likely to present with highest stage cancers ${ }^{4,15,16}$ and show reduced survival. ${ }^{4,18-20}$ Therefore, the most obvious benefit of continuing screening in older women is finding 
Figure 1. An algorithmic approach to breast cancer screening for women over the age of 74 .

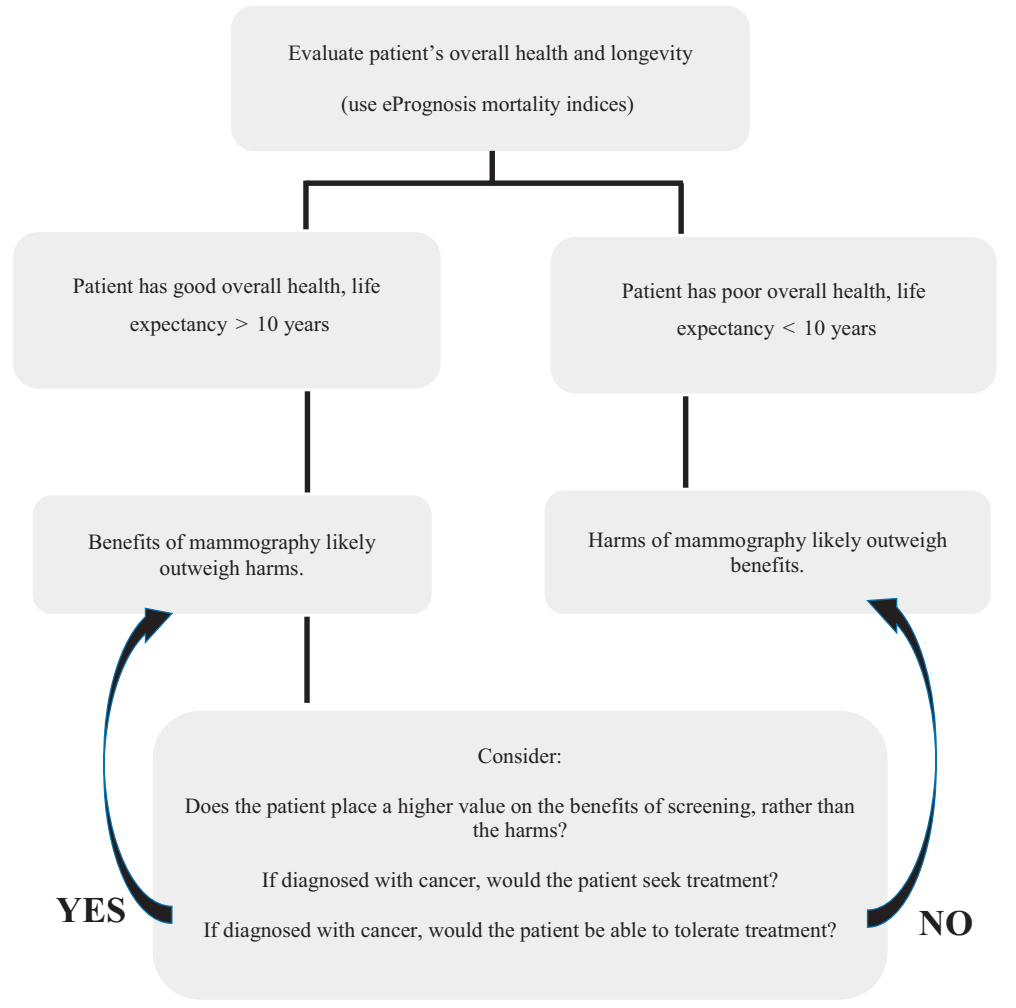

breast cancer at a point when potentially harmful treatment can be minimized, life expectancy maintained, and morbidity avoided.

The potential harms of breast cancer screening in older women include false positive results and overdiagnosis. Among women 75 years and older, 200 out of 1000 who are screened over 10 years will experience a false alarm, ${ }^{10}$ which can cause pain, anxiety, and distress. ${ }^{21,22}$ False positive mammogram results decrease with age. ${ }^{12}$ Overdiagnosis, a phenomenon in which a cancer detected by screening would not have gone on to cause symptoms or death, is a harm of screening that increases with age. ${ }^{10,23,24}$

Follow-up procedures such as additional mammograms, ultrasounds, and breast biopsies may be more painful and frightening for older women who have cognitive impairment (dementia) and other comorbidities (arthritis, hemiparesis). ${ }^{22,25,26}$ Further, treatments for breast cancer (surgery, chemotherapy, and radiation) may confer greater risks in older women and impact their quality of life without prolonging their life.

It is important to communicate the possible harms of breast cancer screening to patients, because many older adults tend to overestimate the benefits of screening and underestimate the harms. ${ }^{27,28}$

\section{Taking into Account General Health, Comorbidity, and Life Expectancy}

Several guidelines recommend screening women who have a life expectancy of at least 10 years and good overall health (Table 1). Based on 2008 US Life Tables, approximately $50 \%$ of 80 -year-old women and $25 \%$ of 85 -year-old women will live at least 10 years (Figure 1). ${ }^{10,29}$

Studies show that breast cancer screening does not benefit older women with severe or multiple comorbidities, due to competing causes of mortality. ${ }^{4,16,20}$ Although women with a life expectancy of less than 10 years are unlikely to experience a mortality reduction from screening mammography, $7,9,10,30$ many women with serious comorbidities are still receiving routine screening mammograms. ${ }^{31,32}$ Among older women, breast cancer risk factors such as lifelong obesity, high bone density, and high breast density are also more predictive of late-life breast 
Figure 2. Life expectancy of women in the United States. ${ }^{10}$ This figure shows that age alone is a crude predictor of life expectancy because considerable variability in longevity exists among women in the United States.

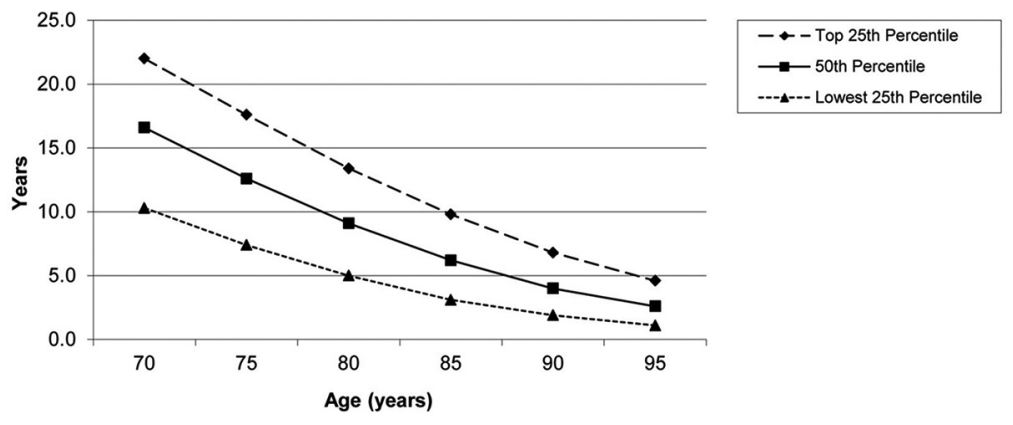

cancer than factors such as age at first birth or age at first menarche. ${ }^{10}$

An algorithm included in this article can help guide the decision-making process (Figure 2). Another resource that may be helpful for physicians is ePrognosis (https://eprognosis.ucsf.edu), a repository of geriatric prognostic indices. These indices incorporate age, comorbidities, and functional status to predict long-term mortality among older women and can be used to corroborate clinical judgment. ${ }^{33}$ For instance, a risk calculator on the ePrognosis website can be used to estimate a woman's probability of living for 10 years or longer by inputting information about the patient's age, BMI, past medical history, and ability to perform normal daily activities. If the 10 -year mortality risk is calculated as $<50 \%$, the life expectancy is estimated to be greater than 10 years, and screening may be recommended to the patient. Another option on ePrognosis is an online breast cancer screening aid. This tool requires input of similar patient information as the risk calculator and then offers a screening recommendation on the final page. Information that a patient may find useful, such as supporting data about benefits and harms of screening, the risk of false positives, and mortality estimates, accompanies the recommendation.

\section{Strategies for an Effective Discussion}

Because the decision to continue breast cancer screening in older women should be most appropriately individualized, it is important to use a shared decision-making process with the patient. Data show that patients appreciate discussions of stopping screening most from a trusted clinician. Therefore, these conversations should take place between the primary care physician and the patient. It is logical to start discussing when to stop screening as a woman nears 74 , which is when the recommendations change. That way, the clinician and patient can have a series of conversations about the topic of screening, how often to screen, and when or whether to stop screening at a certain age. Screening conversations can also include a partner or family member who can help delineate health priorities.

Key shared decision-making elements for the clinician are discussing both the risks and benefits of mammography and then assessing the patient's understanding of the information presented. ${ }^{34}$ Conveying numbers using absolute risk reduction, natural frequencies, and descriptive, everyday language (rather than technical jargon) will also improve the patient's comprehension. ${ }^{35}$ When discussing breast cancer screening, it is necessary to explore the patient's preferences as well. For instance, screening mammography should not be performed on women who would not choose further evaluation or treatment based on abnormal screening results. In addition, some patients may find little value in the slight mortality benefit that screening offers and may wish to avoid the potential harms of screening.

Health decision aids are a helpful tool for presenting information about screening mammography to women. They often include visual aids and present risk with absolute risk reductions instead of relative risk reductions, to maximize the patient's understanding. Beth Israel Deaconess Medical Center offers 2 decision aids for older women, 1 xfor women aged 75 to 84 and another for women aged 85 or older. $^{36-38}$ The Center for Medical Psychology and Evidence-Based Decision-Making 


\section{BOX 1: Case-using a health decision aid and the three-talk model to discuss breast cancer screening in older women}

Jane Brown is a 76-year-old woman presenting for a physical. She has well-controlled hypertension, lives on her own, and maintains a physically active lifestyle. Jane has been getting biannual screening mammograms for many years and finds them reassuring because she has personally known women with breast cancer. At this appointment, Jane is wondering if she needs to schedule a screening mammogram.

\section{Choice Talk}

You let your patient know that she can continue with biannual screening, or stop screening altogether, and that you can work with her to reach a decision that would be best for her. To start, you tell her that it is unclear if screening mammograms benefit women over the age of 74 , and you explain why. Then, you offer to discuss her overall health, life expectancy, and personal preferences together with her to decide whether to continue, or stop, biannual screening.

Example: Beyond age 74, it is unknown whether women benefit from routine screening mammograms. This controversy exists because trials of screening mammography did not include women over the age of 74. Some organizations say that women should stop screening when they are 74 years old, whereas others recommend screening to continue as long as the woman is in good overall health and has a life expectancy of more than years. To reach a decision, you and I need to discuss your overall health, review the risks and benefits of screening, and then decide together what the best option would be for you.

\section{Option Talk}

You discuss individual comorbidities and potential risks and benefits of continuing to do screening mammography.

Example: When we take into consideration your age, weight, lack of significant medical conditions, and the ease with which you are able to perform normal daily activities, we see that mammograms may help you live longer. Studies show that the potential benefit of screening mammograms (ie, reducing breast cancer mortality) occurs $\sim 5$ to 10 years after mammography. Because you are likely to live longer than that, screening mammograms may benefit you. Was that clear? What questions do you have for me?

Example: When we look at your list of medical problems as well as your age, the potential harms of screening mammography may outweigh the benefits for you. Would you be willing to undergo surgery, and potentially other treatments if a mammogram were to diagnose a breast cancer? What questions do you have about whether to continue breast cancer screening?

Next, you use a patient decision aid to review the potential harms and benefits of screening mammography in older women. You explain to your patient the risks of false positives and overdiagnosis, as well as the potential mortality benefit, and show her the pictographs that convey this information in the decision aid. Briefly, you review the treatment options for breast cancer, so that each patient considers whether or not she would choose treatment, if cancer was found on her mammograms. Afterward, you assess your patient's understanding.

Example: The benefit of screening mammograms is catching a cancer while it is small, improving the chance that you will only need minor surgery. Studies suggest that, among women who get screening mammograms, 1 less woman out of a 1000 will die of breast cancer in the next 5 years.

There are several potential harms of screening mammograms as well. For instance, 100 women out of a 1000 will experience false positives in the next 5 years, as you can see in this graph. These false positives can cause pain, anxiety, and lead to additional tests. Overdiagnosis, which is finding a cancer that would not have harmed you in your lifetime, is another harm of screening, and the risk for overdiagnosis increases with age. If breast cancer is found, your treatment options are surgery, hormonal therapy, and radiation therapy. Each of these options has risks for side effects and complications, as briefly described in this decision aid. 
To make sure that I explained everything clearly, can you tell me in your own words about the risks and benefits of screening?

\section{Decision Talk}

Now that you have discussed whether screening mammograms are likely to benefit Jane and reviewed the risks and benefits of screening with her, you ask your patient about her preferences for screening.

Example: Now that we've discussed screening in more detail, can you share your thoughts with me? Do the harms of screening concern you more, or do you think that the potential for finding a breast cancer early outweighs the risks of screening?

Last, you integrate your patient's preferences and values into the final decision and remind her that you can revisit this discussion in the future as well.

Example: To summarize, you understand the risks of continuing with breast cancer screening, but you would still like to get biannual mammograms. You've had close friends that passed away from breast cancer, and continuing with screening will give you some peace of mind. Is that correct?

I will order the mammogram for you. Please know that we can always talk about screening again at your next appointment.

also offers a decision aid for women 70 years or older. ${ }^{39}$ These decision aids can be printed out, and they offer more detailed information than the online ePrognosis breast cancer screening aid. The University of Sydney tool is a 24-page interactive worksheet geared specifically for women over 70 that women can print out and work through (http:// www.psych.usyd.edu.au/cemped/docs/Mammogram_ DecisionAid.pdf). ${ }^{39}$

\section{Case (Continued)}

We go through the decision aid with Ms. Brown. She has well-controlled hypertension, does not smoke, and can walk 3 blocks with no assistance. She has not been admitted to the hospital in the last year. The decision aid assigns points to each question (ie, have you ever been diagnosed with cancer, can you walk 3 blocks), and the lower the score (the more negative answers), the more likely that the potential benefits of a mammogram will outweigh the potential harms. Based on her overall good health, it is likely that she would continue to benefit from screening if she decides to continue.

Additional aids can be found on the Ottawa Patient Decision Aids Inventory. ${ }^{40} \mathrm{~A}$ case study is included in this article that shows how to use the Beth Israel health decision aid for women aged 75 to $84,{ }^{37}$ and elements of the three-talk shared decision-making model, ${ }^{41,42}$ to discuss breast cancer screening with older women (Box 1). The threetalk model is a method of ensuring that shared decision making is taking place. It makes sure that the clinician includes a statement about the choice that needs to be made (choice talk), the options to choose between (option talk), and then concludes with a decision that is adherent to the patient's values (decision talk).

Last, framing discussions in terms of the balance between potential benefits of screening and harms has been found to be more effective than simply citing national guideline recommendations. ${ }^{43-46}$ This balance is especially important when explaining that screening mammograms would not be beneficial for a person with multiple comorbidities and a life expectancy of less than 10 years. In women with a shorter life expectancy, it is important to emphasize that the patient is more likely to experience harms than benefits from breast cancer screening. Focusing on interventions that are likely to help the patient over a shorter time frame will likely provide more value. Additional strategies, videos, and practice phrases for communicating prognosis to patients can be found on the ePrognosis website. ${ }^{47}$ Literature suggests that patients prefer to hear recommendations about screening cessation in the context of their other health conditions, rather than being told that they should stop screening. ${ }^{45,46}$

\section{Conclusion}

Although guidelines are conflicting about whether to continue screening mammography in older women, clinicians can use shared decision making 
to help women make decisions about screening. Using these communication strategies and decision aids along with life expectancy calculators, clinicians can fully engage older women in the breast cancer screening process.

To see this article online, please go to: http://jabfm.org/content/ 33/3/473.full.

\section{References}

1. Siegel RL, Miller KD, Jemal A. Cancer statistics. CA: A Cancer Journal for Clinicians 2018;68:7-30.

2. Howlader N, Noone AM, Krapcho M, et al [Internet]. SEER cancer statistics review, 19752009, National Cancer Institute, based on November 2011 SEER data submission, posted to the SEER web site 2012. Bethesda, MD, National Cancer Institute. Available from: https://seer. cancer.gov/csr/1975_2009_pops09/.

3. Hillner BE, Penberthy L, Desch CE, McDonald MK, Smith TJ, Retchin SM. Variation in staging and treatment of local and regional breast cancer in the elderly. Breast Cancer Res Tr 1996;40:75-86.

4. McCarthy EP, Burns RB, Freund KM, Ash AS, et al. Mammography use, breast cancer stage at diagnosis, and survival among older women. J Am Geriatr Soc 2000;48:1226-33.

5. Randolph WM, Goodwin JS, Mahnken JD, Freeman JL. Regular mammography use is associated with elimination of age-related disparities in size and stage of breast cancer at diagnosis. Ann Intern Med 2002;137:783-90.

6. Howlader N, Noone AM, Krapcho M, et al [Internet]. SEER cancer statistics review, 19752012, based on November 2014 SEER data submission, posted to the SEER web site 2015. Bethesda, MD, National Cancer Institute. Available from: http://seer.cancer.gov/csr/1975_2012/.

7. Oeffinger KC, Fontham ETH, Etzioni R, et al. Breast cancer screening for women at average risk: 2015 guideline update from the American Cancer Society. JAMA 2015;314:1599-614.

8. Qaseem A, Lin JS, Mustafa RA, Horwitch CA, Wilt TJ. Screening for breast cancer in average-risk women: a guidance statement from the American College of Physicians. Ann Intern Med 2019;170: 547-60.

9. Siu AL, US Preventive Services Task Force. Screening for breast cancer: U.S. Preventive Services Task Force recommendation statement. Ann Intern Med 2016;164:279-96.

10. Walter LC, Schonberg MA. Screening mammography in older women: a review. JAMA 2014;311: 1336-47.

11. Mandelblatt JS, Cronin KA, Bailey S, et al. Effects of mammography screening under different screening schedules: model estimates of potential benefits and harms. Ann Intern Med 2009;151: 738-47.

12. Barratt A, Howard K, Irwig I, Salkeld G, Houssami N. Model of outcomes of screening mammography: information to support informed choices. BMJ 2005;330:936.

13. Carney PA, Miglioretti DL, Yankaskas BC, et al. Individual and combined effects of age, breast density, and hormone replacement therapy use on the accuracy of screening mammography. Ann Intern Med 2003;138:168-75.

14. Henderson LM, for the Breast Cancer Surveillance Consortium, O'Meara ES, Braithwaite D, Onega T. Performance of digital screening mammography among older women in the United States. Cancer 2015;121:1379-86.

15. Vyas A, Madhavan S, Sambamoorthi U. Association between persistence with mammography screening and stage at diagnosis among elderly women diagnosed with breast cancer. Breast Cancer Res Treat 2014;148:645-54.

16. Badgwell BD, Giordano SH, Duan ZZ, et al. Mammography before diagnosis among women age 80 years and older with breast cancer. JCO 2008; 26:2482-8.

17. American Academy of Family Physicians [Internet]. Breast cancer-clinical preventive service recommendation. American Academy of Family Physicians; 2016 [cited 2019 May 21]. Available from: https://www.aafp.org/patient-care/clinicalrecommendations/all/breast-cancer.html

18. Vacek PM, Skelly JM. A prospective study of the use and effects of screening mammography in women aged 70 and older. J Am Geriatr Soc 2015;63:1-7.

19. Dijck JV, Verbeek AL, Beex LV, et al. Breast-cancer mortality in a non-randomized trial on mammographic screening in women over age 65 . Int $\mathrm{J}$ Cancer 1997;70:164-8.

20. McPherson CP, Swenson KK, Lee MW. The effect of mammographic detection and comorbidity on the survival of older women with breast cancer. J Am Geriatr Soc 2002;50:1061-8.

21. Bond M, Pavey T, Welch K, et al. Systematic review of the psychological consequences of falsepositive screening mammograms. Health Technol Assess 2013;17:1-170.

22. Walter LC, Eng C, Covinsky KE. Screening mammography for frail older women: what are the burdens? J Gen Intern Med 2001;16:779-84.

23. Welch HG, Black WC. Overdiagnosis in cancer. J Natl Cancer Inst 2010;102:605-13.

24. Puliti D, Duffy SW, Miccinesi G, et al. Overdiagnosis in mammographic screening for breast cancer in Europe: a literature review. J Med Screen 2012;19:42-56. 
25. Sox HC. Screening for disease in older people. J Gen Intern Med 1998;13:424-5.

26. Raik BL, Miller FG, Fins JJ. Screening and cognitive impairment: ethics of forgoing mammography in older women. J Am Geriatr Soc 2004;52:440-4.

27. Schwartz LM, Woloshin S, Fowler FJ, Jr, Welch HG. Enthusiasm for cancer screening in the United States. JAMA 2004;291:71-8.

28. Hoffman RM, Lewis CL, Pignone MP, et al. Decision-making processes for breast, colorectal, and prostate cancer screening: the DECISIONS survey. Med Decis Making 2010;30:53-64S.

29. Arias E. United States life tables 2008. National Vital Statistics Reports 2012;61:3.

30. National Comprehensive Cancer Network [Internet]. Breast cancer screening and diagnosis. Version 1. 2016. Available from: https://www.nccn.org/.

31. Sima CS, Panageas KS, Schrag D. Cancer screening among patients with advanced cancer. JAMA 2010;304:1584-91.

32. Tan A, Kuo YF, Goodwin JS. Potential overuse of screening mammography and its association with access to primary care. Med Care 2014;52:490-5.

33. Yourman LC, Lee SJ, Schonberg MA, Wildera EW, Smith AK. Prognostic indices for older adults: a systematic review. JAMA 2012;307:18292. Prognostic indices available from: http://www. eprognosis.org.

34. Schrager SB, Phillips G, Burnside E. A simple approach to shared decision making in cancer screening. Fam Pract Manag 2017;24:5-10.

35. Schrager S. Five ways to communicate risks so that patients understand. Fam Pract Manag 2018;25: 28-31.

36. Schonberg MA, Hamel MB, Davis RB, et al. Development and evaluation of a decision aid on mammography screening for women aged 75 and older. JAMA Intern Med 2014;174:417-24.

37. Schonberg $M$ [Internet]. Should I continue having mammograms? For women age 75 to 84 Years. Beth Israel Deaconess Medical Center; 2013. Available from: https://www.bidmc.org/-/media/ files/beth-israel-org/research/research-by-department/ medicine/general-medicine-research/research-faculty/ decision-aid-758432019.pdf.

38. Schonberg M [Internet]. Should I continue having mammograms? For women age 85 or older. Beth Israel Deaconess Medical Center; 2013. Available from: https://www.bidmc.org/-/media/files/bethisrael-org/research/research-by-department/medicine/ general-medicine-research/research-faculty/decisionaid-8532019.pdf.

39. University of Sydney [Internet]. Should I continue having mammograms to screen for breast cancer? A decision aid for women aged 70 and older at their next screening mammogram. 2003. Available from: http://www.psych.usyd.edu.au/cemped/docs/ Mammogram_DecisionAid.pdf.

40. The Ottawa Hospital Research Institute [Internet]. Patient decision aids. 2019. Available from: https:// decisionaid.ohri.ca/AZsearch.php?criteria=breast + cancer $+\&$ search $=$ Go.

41. Elwyn G, Frosch D, Thomson R, et al. Shared decision making: a model for clinical practice. J Gen Intern Med 2012;27:1361-7.

42. Schrager SL [Internet]. Breast cancer screening shared decision making toolkit. Madison: University of Wisconsin-Madison School of Medicine \& Public Health; 2018. Available from: https://www.hipxchange.org/ScreeningMammo.

43. Schonberg MA, Ramanan RA, McCarthy EP, Marcantonia ER. Decision making and counseling around mammography screening for women aged 80 or older. J Gen Intern Med 2006;21:979-85.

44. Torke AM, Schwartz P, Holtz LR. Older adults and forgoing cancer screening: "I think it would be strange.” JAMA Intern Med 2013;173:526-31.

45. Schoenborn NL, Lee K, Pollack CE, et al. Older adults' views and communication preferences about cancer screening cessation. JAMA Intern Med 2017;177:1121-8.

46. Schoenborn NL, Boyd CM, Lee SJ, Cayea D, Pollack CE. Communicating about stopping cancer screening: comparing clinicians' and older adults perspectives. Gerontologist 2019;99:S67-76.

47. Lee S, Smith A, Widera E, Yourman L, Schonberg M, Ahalt C [Internet]. Prognosis communication. ePrognosis. 2020. Available from: https://eprognosis. ucsf.edu/communication/index.php.

48. Practice bulletin number 179: breast cancer risk assessment and screening in average-risk women. Obstet Gynecol 2017;130: 241-3.

49. Monticciolo DL, Newell MS, Hendrick ER, et al. Breast cancer screening for average-risk women: recommendations from the ACR Commission on Breast Imaging. J Am Coll Radiol 2017;14:1137-43.

50. Canadian Task Force on Preventive Health Care [Internet]. Breast cancer update. 2018 [cited 2019 May 21]. Available from: https://canadiantaskforce. ca/guidelines/published-guidelines/breast-cancerupdate/.

51. National Health Service [Internet]. National Health Service breast screening programme overview. 2015 [cited 2019 May 27]. Available from: https://www.gov.uk/guidance/breast-screeningprogramme-overview.

52. Royal Australian College of General Practitioners. Guidelines for preventive activities in general practice. 9th ed. East Melbourne: Royal Australian College of General Practitioners; 2018. 